\title{
Accessory Atrioventricular Myocardial Pathways in Mouse Heart Development: Substrate for Supraventricular Tachycardias
}

\author{
NATHAN D. HAHURIJ, DENISE P. KOLDITZ, REGINA BÖKENKAMP, ROGER R. MARKWALD, MARTIN J. SCHALIJ, \\ ROBERT E. POELMANN, ADRIANA C. GITTENBERGER-DE GROOT, AND NICO A. BLOM
}

Departments of Pediatric Cardiology [N.D.H., R.B., N.A.B.], Anatomy and Embryology [N.D.H., D.P.K., R.E.P., A.C.G.], and Cardiology [D.P.K., M.J.S.], Leiden University Medical Center, Leiden, 2300 RC, The Netherlands; Cardiovascular Developmental Biology Center [R.R.M.], Children's Research Institute, Medical University of South Carolina, Charleston, South Carolina 29425

\begin{abstract}
Atrioventricular reentry tachycardia (AVRT) requiring an accessory atrioventricular pathway (AP) is the most common type of arrhythmia in the perinatal period. The etiology of these arrhythmias is not fully understood as well as their capability to dissipate spontaneously in the first year of life. Temporary presence of APs during annulus fibrosus development might cause this specific type of arrhythmias. To study the presence of APs, electrophysiological recordings of ventricular activation patterns and immunohistochemical analyses with antibodies specifically against atrial myosin light chain 2 (MLC-2a), Periostin, Nkx2.5, and Connexin-43 were performed in embryonic mouse hearts ranging from 11.5 to 18.5 days post-conception $(\mathrm{dpc})$. The electrophysiological recordings revealed the presence of functional APs in early $(13.5-15.5 \mathrm{dpc})$ and late (16.5-18.5 dpc) postseptated stages of mouse heart development. These APs stained positive for MLC-2a and Nkx2.5 and negative for Periostin and Connexin-43. Longitudinal analyses showed that APs gradually decreased in number $(p=0.003)$ and size $(p=0.035)$ at subsequent developmental stages $(13.5-18.5 \mathrm{dpc})$. Expression of periostin was observed in the developing annulus fibrosus, adjacent to APs and other locations where formation of fibrous tissue is essential. We conclude that functional APs are present during normal mouse heart development. These APs can serve as transient substrate for AVRTs in the perinatal period of development. (Pediatr Res 70: 37-43, 2011)
\end{abstract}

$\mathrm{I}_{\mathrm{t}}^{\mathrm{n}}$ the fetus and newborn, atrioventricular (AV) reentry tachycardia (AVRT) is a relatively common tachyarrhythmia. AVRT requires the presence of an accessory AV pathway (AP) that crosses the isolating annulus fibrosus. Initial management of AVRT can be difficult, but the natural course is benign and most children remain symptom-free without medication after the age of 1 year (1-3).

Annulus fibrosus formation plays a key role in the separation of atrial and ventricular myocardium in the AV canal (4) and encompasses interactions between several molecular pathways $(5,6)$, which have not yet been completely identified. Periostin, a member of the fascilin gene family (7), is highly expressed in collagen rich-fibrous connective tissue in the developing heart that is subjected to high mechanical stress $(8,9)$. Recently, it has been revealed that periostin directly

Received October 21, 2010; accepted January 4, 2011

Correspondence: Nico A. Blom, M.D., Ph.D., Department of Pediatric Cardiology, Leiden University Medical Center (LUMC), PO Box 9600, 2300RC Leiden, The Netherlands; e-mail: n.a.blom@lumc.nl

Supported by the Gisela Thier Foundation [N.D.H.] regulates collagen-I fibrillogenesis (8). The inductive role of periostin on fibrous tissue formation seems to be of special interest in annulus fibrosus anlage (10,11).

In mature hearts, the atrial and ventricular myocardium are electrically separated in two myocardial compartments, which are interconnected via the AV conduction axis, i.e. the $\mathrm{AV}$ node and bundle of His (5). At early embryonic stages, however, the atrial and ventricular myocardium are continuous in the primitive AV canal, establishing a ventricular base-to-apex activation pattern. At later stages, ventricular conduction transforms into the mature apex-to-base activation. The switch from ventricular base-to-apex in apex-to-base activation is suggested to be closely related to the completion of ventricular septation and annulus fibrosus development $(12,13)$. Nevertheless, contemporary electrophysiological studies in embryonic mouse hearts have shown that before ventricular septation is completed, a mature apex-to-base activation is already present, suggesting that the AV conduction axis is functional far before ventricular septation has finished $(14,15)$.

It has been hypothesized that temporary persistence of the embryonic AV myocardial continuity during annulus fibrosus development might serve as APs. Consequently, these transient APs may provide the substrate for AVRT in the perinatal period and explain its self-limiting character. Studies in avian demonstrated that antegrade conducting APs are present at late postseptated stages of heart development, which gradually diminish during fetal life (12). In mammalian hearts $(15,16)$, including human $(17,18)$, APs have also been described throughout cardiac development. Thus far, the description of APs in mammals mainly focused on the electrophysiological properties of primitive AV canal myocardium in preseptated hearts (15) and neither late stages of fetal heart development nor the exact course of APs at the developing annulus fibrosus were provided.

The current study for the first time describes the presence of "functional" APs in early and late postseptated stages of mouse heart development. Furthermore, we show that perios-

\footnotetext{
Abbreviations: AP(s), accessory atrioventricular pathway(s); AV, atrioventricular; AVRT, AV reentry tachycardia; bpm, beats per minute; CCS, cardiac conduction system; dpc, days post-conception; HR, heart rate; LVA, left ventricular apex; LVB, left ventricular base; RA, right atrium; RVB, right ventricular base
} 
tin is highly expressed in the developing annulus fibrosus at locations where separation of atrial and ventricular myocardium is mandatory.

\section{MATERIALS AND METHODS}

Animals and preparation of hearts. Animal experiments were approved by the Institutional Animal Care and Use Committee of the Leiden University Medical Center. Embryonic hearts were obtained from two separate WT mouse strains, C57B16/Jico and CD1. The presence of a vaginal plug 1 day after breeding was considered to be 0.5 days post-conception $(\mathrm{dpc})$. Embryos of subsequent stages were used, ranging from 11.5 to $18.5 \mathrm{dpc}(n=48)$. After cervical dislocation of the pregnant mouse, the uterus horns containing the embryos were harvested and placed in a Petri dish filled with Tyrode's solution containing $130 \mathrm{NaCl}, 4 \mathrm{KCl}, 1.2 \mathrm{KH}_{2} \mathrm{PO}_{4}, 0.6 \mathrm{MgSO}_{4} \cdot 7 \mathrm{H}_{2} \mathrm{O}, 20$ $\mathrm{NaHCO}_{3}, 1.5 \mathrm{CaCl}_{2} \cdot 2 \mathrm{H}_{2} \mathrm{O}$, and 10 glucose $(\mathrm{mmol} / \mathrm{L}$; chemicals obtained from Merck, Darmstad, Germany) at $37^{\circ} \mathrm{C}$. Subsequently, in Tyrode's solution of $0^{\circ} \mathrm{C}$, the embryonic hearts were dissected one-by-one.

Electrophysiologic recordings. In the electrophysiology setup, the embryonic hearts were attached with fine wires through extracardiac tissue in a fluid heated, temperature-controlled (Physitemp Instruments Inc, Clifton, NJ) Petri dish of $35.5-37^{\circ} \mathrm{C}$ onto a layer of agarose gel (Roche Diagnostics, Mannheim, Germany). During the 3-min equilibration period and subsequent electrophysiological recordings, the hearts were constantly super-perfused with Carbogenated $\left(95 \% \mathrm{O}_{2}\right.$ and $\left.5 \% \mathrm{CO}_{2}\right)$ Tyrode's solution at $37^{\circ} \mathrm{C}$. Unipolar tungsten electrodes (tip: 1-2 $\mu \mathrm{m}$; impedance: 0.9-1.0 M $\Omega$; WPI Inc, Sarasota, FL) were positioned on the right atrium (RA), right ventricular base (RVB), left ventricular base (LVB), and left ventricular apex (LVA; Fig. 1), using microscopic-guided micromanipulators (Wild Heerbrugg, M7A, Switzerland). $\mathrm{An} \mathrm{Ag} / \mathrm{AgCl}$ electrode in the Petri dish served as reference electrode.

All electrograms were recorded under stable sinus rhythm with a highgain, low-noise, direct-current bioamplifier system (Iso-DAM8A; WPI Inc, Berlin, Germany), with four isolated preamplifier modules with an output impedance of $>10^{12} \Omega$. The signals were band-passed ( $\left.300 \mathrm{~Hz}-1 \mathrm{kHz}\right)$ and notch-filtered $(50 \mathrm{~Hz})$ before being digitized at a sample rate of $1 \geq \mathrm{kHz}$ with a computerized recording system (Prucka Engineering Inc, Houston, TX) and stored on optical disks for offline analysis.

The basal cycle length/heart rate (HR) of each heart and local depolarization time of each electrode, defined as maximal negative deflection on the unipolar electrogram, were calculated by the average of 10 consecutive beats. Subsequently, ventricular activation patterns of each heart were determined: base-to-apex if the RVB or LVB depolarized $1 \geq$ ms before the LVA; apex-to-base if the LVA depolarized $1 \geq \mathrm{ms}$ before the RVB or LVB;

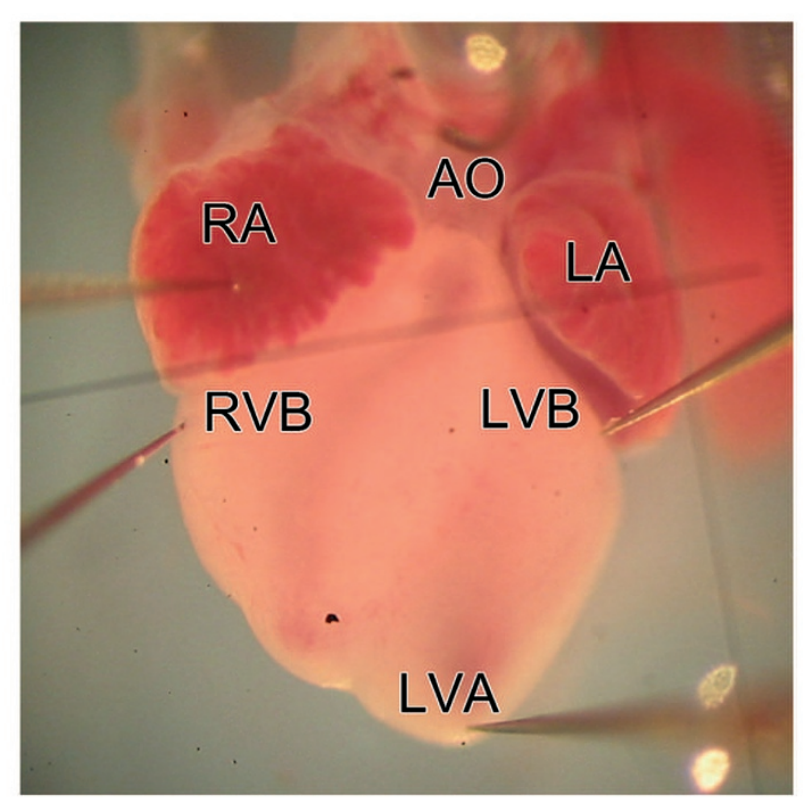

Figure 1. Positioning of the unipolar electrodes for electrophysiological recordings. Four Tungsten electrodes were placed on the epicardial surface of the embryonic hearts, at the RA, RVB, LVB, and LVA. AO, aorta. concurrent if the depolarization time between the LVA and LVB or RVB was $<1 \mathrm{~ms}$. After recordings, all the hearts were fixed in $4 \%$ paraformaldehyde for immunohistochemical processing.

Immunohistochemistry and immunofluorescence. Standard immunohistochemistry was performed with 1/2000 atrial myosin light chain 2 (MLC-2a, gift from S.W. Kubalak, Charleston, SC), 1/1000 Periostin (R.R. Markwald, Charleston, SC), and 1/200 Connexin-43 (Cx43; Sigma Chemical Co., C6219, St. Louise, MO) specific antibodies. Immunofluorescent double staining procedures were performed combining 1/250 periostin and 1/2000 NK2 transcription factor-related locus 5 (Nkx2.5; sc-8697, Santa Cruz Biotechnology, Heidelberg, Germany) specific antibodies. Detailed description of the staining procedures can be found in previous publications (10-12).

Morphology and statistics. All hearts were studied for the presence of APs including their location at the developing annulus fibrosus using an Olympus $\mathrm{BH}-2$ lighting microscope. AP-width was calculated by counting the number of subsequent MLC-2a-stained sections through which a single accessory connection could be followed and multiplied by $25 \mu \mathrm{m}$ (distance between subsequent MLC-2a-stained sections).

Statistical analysis of HR and AV conduction time was performed with a $t$ test if values were equally distributed (skewness is -1 ); otherwise, a Mann-Whitney $U$ test was used. Analyses of AP-number and AP-width were performed with a univariate analyses of variance (unianova). A $P$ value of $<0.05$ (two-tailed) was considered to be significant. The SPSS15.0 software package (SPSS Inc, Chicago, IL) was used for all analyses.

\section{RESULTS}

Preseptated hearts $(11.5-13.5 d p c ; \mathrm{n}=6)$. The mean recorded HR in preseptated hearts was $94 \pm 24$ beats per minute (bpm) with a mean AV interval of $84 \pm 13 \mathrm{~ms}$. Comparable with previous studies $(14,15)$, most preseptated hearts $(67 \%)$ already showed LVA activation before RVB or $\mathrm{LVB}$ activation, indicating that the $\mathrm{AV}$ conduction axis is functional before ventricular septation has been completed. In two hearts, concurrent ventricular apex and base activation patterns were observed (Table 1).

Early postseptated hearts (13.5-15.5 dpc; $\mathrm{n}=29)$. In early postseptated hearts, a mean HR of $115 \pm 41 \mathrm{bpm}$ was recorded with a mean $\mathrm{AV}$ interval of $80 \pm 17$ ms. Interestingly, only $38 \%$ of early postseptated hearts showed an apexto-base ventricular activation pattern, and the largest group showed base-to-apex and concurrent ventricular activation patterns $(62 \%)$. Concurrent apex and base activation was recorded in the majority of early postseptated hearts (48\%). More detailed analyses of concurrent activated hearts showed that in most of these hearts $(41 \%)$, concurrent activation occurred between the LVB and LVA. In two hearts (7\%), the RVB was activated before the LVA, and also in two hearts (7\%), the LVB was activated before LVA (Table 1). Statistical analyses of AV conduction time showed no significant differences $(P=\mathrm{NS})$ between the mean AV conduction time in apex-to-base $(78 \pm 12 \mathrm{~ms} ; n=11)$ and base-to-apex and concurrent $(81 \pm 20 \mathrm{~ms} ; n=14)$ activated hearts.

Late postseptated hearts $(16.5-18.5 \mathrm{dpc} ; \mathrm{n}=13)$. The mean HR recorded in these hearts was $95 \pm 27 \mathrm{bpm}$ with a mean AV interval of $81 \pm 18 \mathrm{~ms}$. A mature apex-to-base activation pattern was observed in only $46 \%$ of the hearts $(n=$ 6). In a relatively large group of hearts, activation of the LVB before the LVA was recorded $(31 \%)$. Concurrent apex and base activation was observed in $15 \%$, by which concurrent activation only occurred between the LVB and LVA. Furthermore, activation of the RVB before the LVA was observed in one heart (Table 1). Analyses of the mean AV conduction time showed no significant difference $(P=\mathrm{NS})$ in apex-to-base 
Table 1. Summary of ventricular activation patterns in pre-, early post- and late postseptated hearts

\begin{tabular}{|c|c|c|c|c|}
\hline Group, age, (n) & $\begin{array}{l}\mathrm{HR}(\mathrm{bpm}) \\
\text { mean } \pm \mathrm{SD}\end{array}$ & $\begin{array}{l}\mathrm{AV} \text {-interval }(\mathrm{ms}) \\
\text { mean } \pm \mathrm{SD}\end{array}$ & \multicolumn{2}{|c|}{ Ventricular activation pattern, $n(\%)$} \\
\hline \multirow{2}{*}{$\begin{array}{l}\text { Preseptated, } 11.5-13.5 \mathrm{dpc} \\
\quad(n=6)\end{array}$} & $94 \pm 24(66-135)$ & $83 \pm 13(64-105)$ & $\mathrm{LVA}>\mathrm{LVB} / \mathrm{RVB}$ & $4(67)$ \\
\hline & & & Concurrent & $2(33)$ \\
\hline \multirow{6}{*}{$\begin{array}{l}\text { Early postseptated, } 13.5-15.5 \mathrm{dpc} \\
\qquad(n=9)\end{array}$} & $115 \pm 41(67-246)$ & $80 \pm 17(44-112)$ & $\mathrm{LVA}>\mathrm{LVB} / \mathrm{RVB}$ & $11(38)$ \\
\hline & & & $\mathrm{LVB}>\mathrm{LVA}$ & $2(7)$ \\
\hline & & & $\mathrm{RVB}>\mathrm{LVA}$ & $2(7)$ \\
\hline & & & Concurrent & $14(48)$ \\
\hline & & & $\mathrm{LVA}=\mathrm{LVB}$ & $12(41)$ \\
\hline & & & $\mathrm{LVA}=\mathrm{RVB}$ & $2(7)$ \\
\hline \multirow{5}{*}{$\begin{array}{l}\text { Late postseptated, } 16.5-18.5 \mathrm{dpc} \text {, } \\
\qquad(n=13)\end{array}$} & $95 \pm 27(63-146)$ & $81 \pm 18(56-110)$ & $\mathrm{LVA}>\mathrm{LVB} / \mathrm{RVB}$ & $6(46)$ \\
\hline & & & $\mathrm{LVB}>\mathrm{LVA}$ & $4(31)$ \\
\hline & & & $\mathrm{RVB}>\mathrm{LVA}$ & $1(8)$ \\
\hline & & & Concurrent & $2(15)$ \\
\hline & & & $\mathrm{LVA}=\mathrm{LVB}$ & $2(15)$ \\
\hline
\end{tabular}

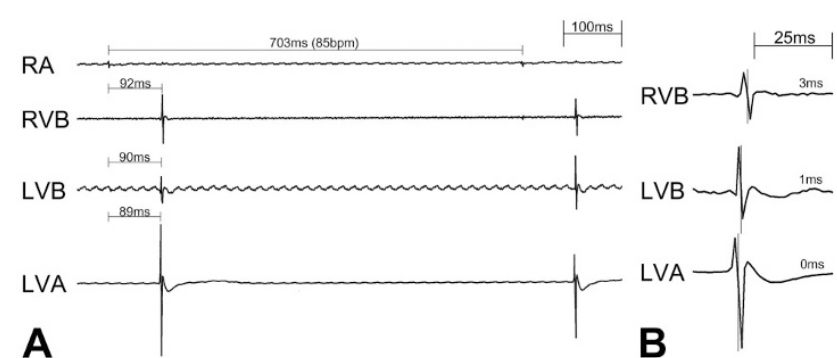

Figure 2. Representative electrophysiological recording of an apex-to-base activated heart. (A) Recording of an early postseptated embryonic heart of $13.5 \mathrm{dpc}$ with a cycle length of $703 \mathrm{~ms}(85 \mathrm{bpm})$. The LVA is activated $89 \mathrm{~ms}$ after the RA, followed by the LVB (90 ms) and RVB (92 ms). (B) Magnification of ventricular activation patterns, showing that the maximal negative deflection at the LVA precedes $1 \mathrm{~ms}$ before LVB and $3 \mathrm{~ms}$ before RVB activation, thereby creating a ventricular apex-to-base activation.

(80 $\pm 22 \mathrm{~ms} ; n=6)$ and base-to-apex and concurrent (82 \pm $16 \mathrm{~ms} ; n=7$ ) activated hearts.

Examples of unipolar-electrophysiological recordings of apex-to-base, base-to-apex, and concurrent activated hearts are shown in Figures 2 and 3.

APs during cardiac development. In all preseptated hearts $(n=6)$, the MLC-2a-stained sections showed a myocardial continuity between the atria and ventricles over the primitive $\mathrm{AV}$ canal. At several locations in the left and right AV ring, separation of atrial and ventricular myocardium by the developing annulus fibrosus was observed (Fig. $4 A, B$, and $D$ ). The primitive ventricular septum was already present at $11.5 \mathrm{dpc}$, and ventricular septation was completed between 13.5 and $14.5 \mathrm{dpc}$. At the dorsal side of the heart, a broad myocardial continuity between the atria and ventricles was observed, i.e. the AV conduction axis (data not shown). At $12.5 \mathrm{dpc}$, expression of $\mathrm{Cx} 43$ was present in the working myocardium of both atria and ventricles, whereas $\mathrm{Cx} 43$ expression was absent in the myocardium of the complete AV canal (Fig. $4 C$ and $E$ ).

In all early postseptated hearts $(13.5-15.5 \mathrm{dpc} ; n=29)$, APs were found around both the mitral and tricuspid orifice of the AV canal. Some of the APs consisted of a single strand of cardiomyocytes, whereas others comprised broad myocardial continuities. At these stages, $\mathrm{Cx} 43$ was clearly present in the working myocardium of the atria and ventricles; however, all

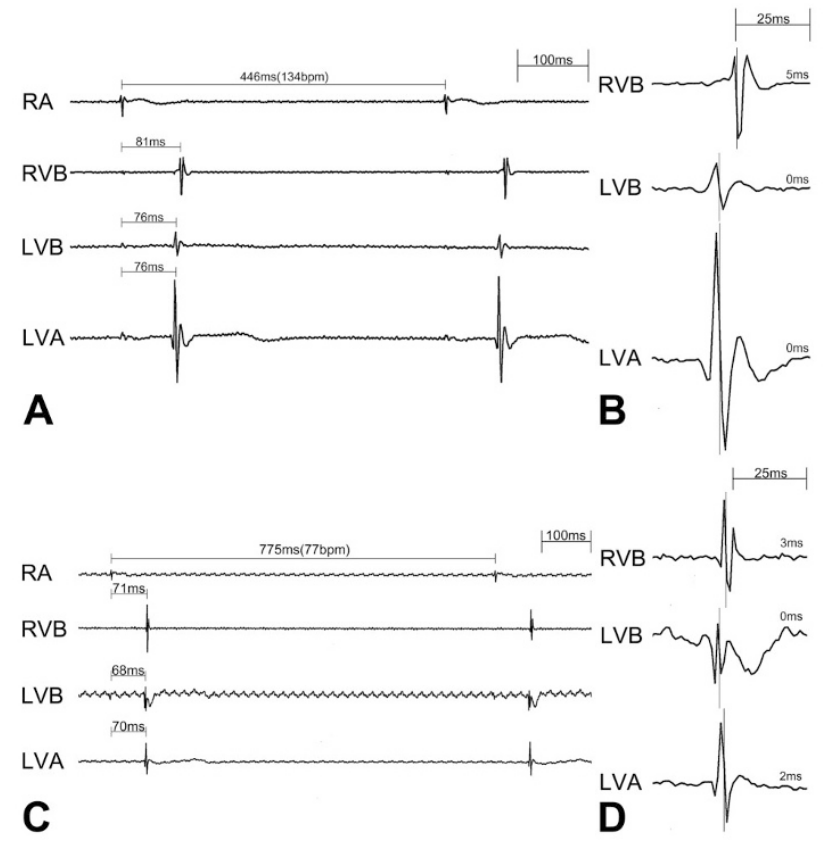

Figure 3. Representative electrophysiological recordings of concurrent apex and base and base-to-apex activated hearts. $(A)$ Recording of an early postseptated heart of $15.5 \mathrm{dpc}$ with a cycle length of $446 \mathrm{~ms}(134 \mathrm{bpm})$. Seventy-six milliseconds after RA activation, first ventricular activation occurs at both the LVA and LVB, followed by RVB activation $(81 \mathrm{~ms})$. (B) Magnification of ventricular activation patterns, showing that the maximal negative deflection of the RVB is $5 \mathrm{~ms}$ after LVA and LVB activation. Consequently, this heart shows a concurrent LVA and LVB activation pattern. (C) Recording of a late postseptated heart of $16.5 \mathrm{dpc}$ with a cycle length of $775 \mathrm{~ms}$ (77 bpm). First ventricular activation was observed $68 \mathrm{~ms}$ after RA activation at the LVB. Subsequently, the LVA and RVB were activated at 70 and $71 \mathrm{~ms}$, respectively. $(D)$ Magnification of ventricular activation patterns, indicating that the maximal negative deflection at the LVB precedes $2 \mathrm{~ms}$ before LVA and $3 \mathrm{~ms}$ before RVB activation, thereby creating a base-to-apex ventricular activation.

APs were negative for $\mathrm{Cx} 43$ (Fig. $4 G$ and $H$ ). At early postseptated stages, APs were more often located around the mitral orifice $(63 \% ; p=0.000)$, and analyses of the AP-width also showed a larger mean total AP-width at that specific region $(p=0.000$; Table 2$)$. Interestingly, in almost all early postseptated hearts (24/29), a broad Cx43 negative AP was present at the anterolateral position of the left $\mathrm{AV}$ junction 


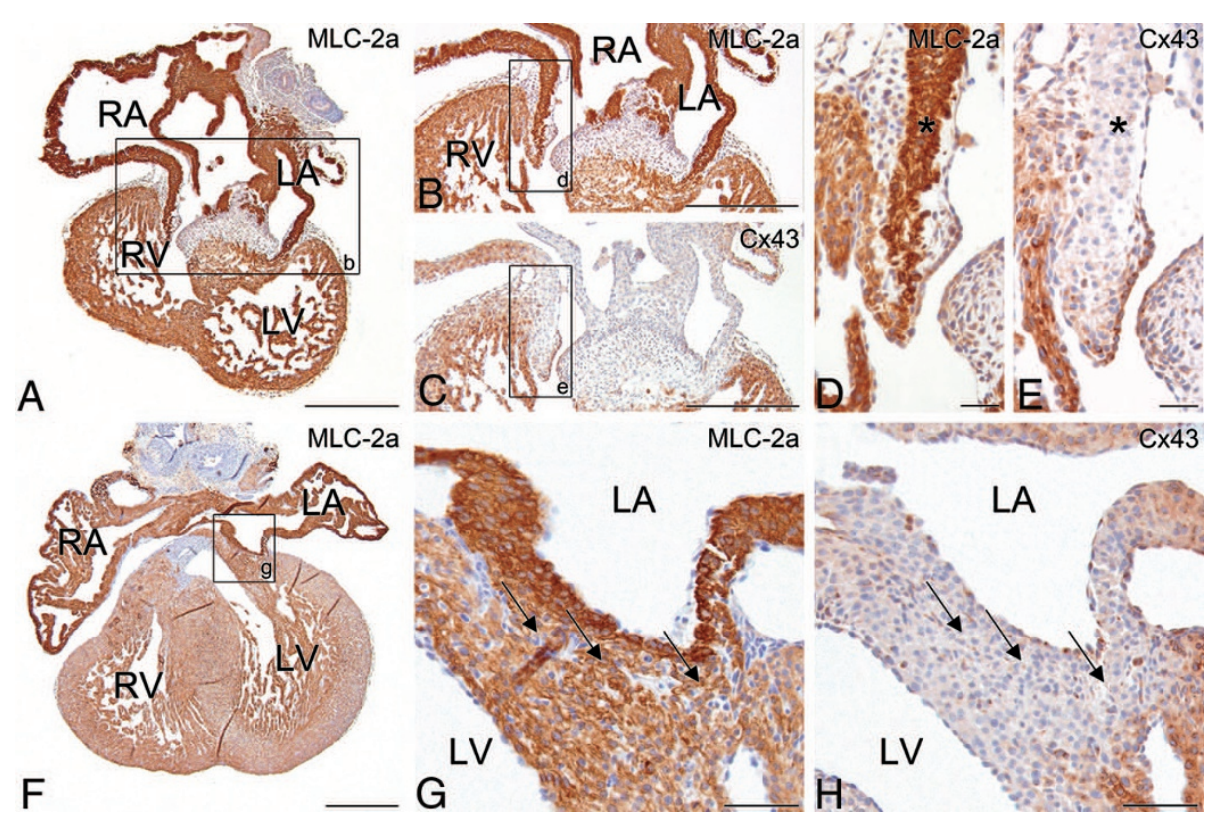

Figure 4. Connexin-43 (Cx43) expression in the AV junction in pre- and postseptated hearts. (A) Frontal MLC-2a-stained section of a preseptated heart of $12.5 \mathrm{dpc}$. In the AV junctional area $[(B)$ magnification of boxed area in (A)], Cx43 expression was absent $[(C)$ consecutive section of $(A)]$, whereas $\mathrm{Cx} 43$ was clearly present in the working myocardium of atria and ventricles $(C)$. ( $D$ and $E$ ) Magnifications of boxed areas in $(B)$ and $(C)$, respectively, show details of the right AV junctional myocardium positive for MLC-2a [asterisk in $(D)$ ] and negative for $\mathrm{Cx} 43$ [asterisk in $(E)$ ]. $(G)$ Frontal section of a 15.5 dpc MLC-2a-stained heart. $(G)$ Magnification of boxed area in $(F)$ shows the large anterolateral AP observed in $n=$ 37 of total $n=42$ postseptated hearts. Arrows in $(G)$ indicate the exact locations of myocardial AV connections. The myocardium of the AV junction including these connections is negative for $\mathrm{Cx} 43$ [arrows in $(H)]$. RV, right ventricle; LA, left atrium; LV, left ventricle. Scale bar: $A-C$ and $F=$ $300 \mu \mathrm{m} ; D, E=30 \mu \mathrm{m} ; G, H=60 \mu \mathrm{m}$.
Table 2. Summary of morphological analyses of APs in early and late postseptated hearts

\begin{tabular}{|c|c|c|c|}
\hline & $\begin{array}{c}\text { Early } \\
\text { postseptated, } \\
13.5-15.5 \mathrm{dpc} \\
(n=29)\end{array}$ & $\begin{array}{c}\text { Late } \\
\text { postseptated } \\
16.5-18.5 \mathrm{dpc} \\
(n=13)\end{array}$ & $\begin{array}{c}\text { Statistics } \\
\text { (early } v s \text { late) }\end{array}$ \\
\hline Mean number of APs & 8.1 & 5.2 & $P=0.003$ \\
\hline $\begin{array}{l}\text { Mean number } \\
\text { left-sided APs }\end{array}$ & 5.1 & 3.1 & $P=0.000$ \\
\hline $\begin{array}{l}\text { Mean number } \\
\text { right-sided APs }\end{array}$ & 3.0 & 2.1 & $P=\mathrm{NS}$ \\
\hline $\begin{array}{l}\text { Statistics mean AP } \\
\text { number (left } v s \\
\text { right) }\end{array}$ & $P=0.000$ & $P=\mathrm{NS}$ & - \\
\hline $\begin{array}{l}\text { Mean width }(\mu \mathrm{m}) \\
\text { of APs }\end{array}$ & 347 & 214 & $P=0.035$ \\
\hline $\begin{array}{c}\text { Mean width }(\mu \mathrm{m}) \\
\text { left-sided APs }\end{array}$ & 238 & 138 & $P=0.000$ \\
\hline $\begin{array}{l}\text { Mean width }(\mu \mathrm{m}) \\
\text { right-sided APs }\end{array}$ & 109 & 76 & $P=\mathrm{NS}$ \\
\hline $\begin{array}{l}\text { Statistics mean } \\
\text { AP-width }(\mu \mathrm{m} ; \\
\text { left } v s \text { right })\end{array}$ & $P=0.000$ & $P=0.028$ & - \\
\hline
\end{tabular}

connecting the left atrial myocardium and left ventricular myocardium along its free wall (Fig. $4 F-H$ ).

In all late postseptated hearts $(16.5-18.5 \mathrm{dpc} ; n=13)$, APs were still observed around the mitral and tricuspid orifice. The expressions pattern of $\mathrm{Cx} 43$ was similar compared with earlier stages, and all APs were still Cx43 negative (data not shown). Although the mean total AP-width at these stages was largest at the mitral orifice $(p=0.028)$, no differences were found between the mean number of APs at the mitral and tricuspid orifice $(p=\mathrm{NS})$. Compared with earlier stages, the mean number of APs per heart around the mitral orifice had decreased significantly $(p=0.000)$, whereas no significant decrease was observed at the tricuspid orifice $(p=0.136$; Table 2). Furthermore, the anterolateral AP at the left AV junction was present in all hearts (13/13).

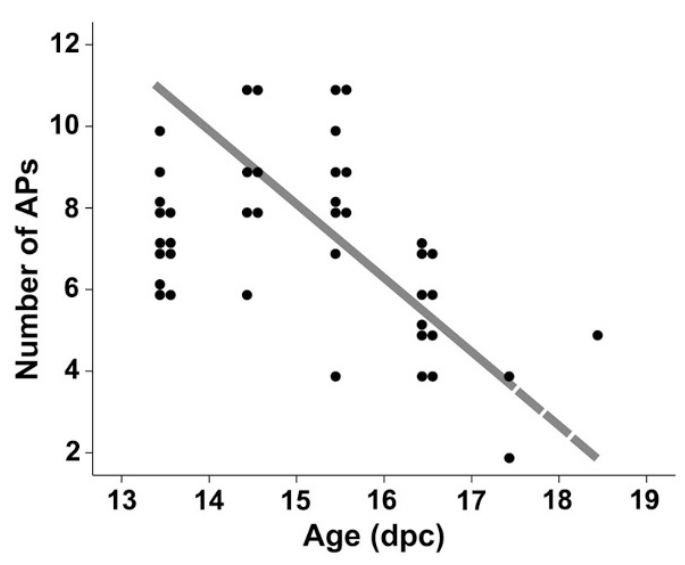

Figure 5. The course of APs in postseptated mouse hearts. The graph schematically represents the course of APs around both the developing tricuspid and mitral valve orifice in postseptated mouse hearts $(n=42)$. Each black circle represents a heart in which a specific number of APs was observed as indicated on the $Y$ axis, at subsequent developmental stages $(X$ axis). The gray transparent line indicates the hypothesized course of APs at the developing annulus fibrosus.

Longitudinal analyses of AP-number and AP-width in all postseptated hearts of subsequent developmental stages (13.5$18.5 \mathrm{dpc} ; n=42$ ) showed significant decrease both in mean number of APs ( $p=0.003$; Fig. 5) and mean total AP-width $(p=0.035)$. Furthermore, differences were observed in the rate by which APs disappeared around the mitral and tricuspid orifice, which appeared significantly faster at the left side of the AV junction $(p=0.015)$.

Periostin expression in relation to annulus fibrosus development and APs. Expression of periostin was present in all embryonic and fetal stages $(11.5-18.5 \mathrm{dpc})$ and specifically limited to the epicardium, the endothelial lining of atrial and ventricular trabeculae, the subendocardial region of both outflow and AV cushions, and the interstitial fibroblasts flanked by working myocardium in the atria and ventricles. At later stages $(>14.5 \mathrm{dpc})$, strong expression was also observed in 

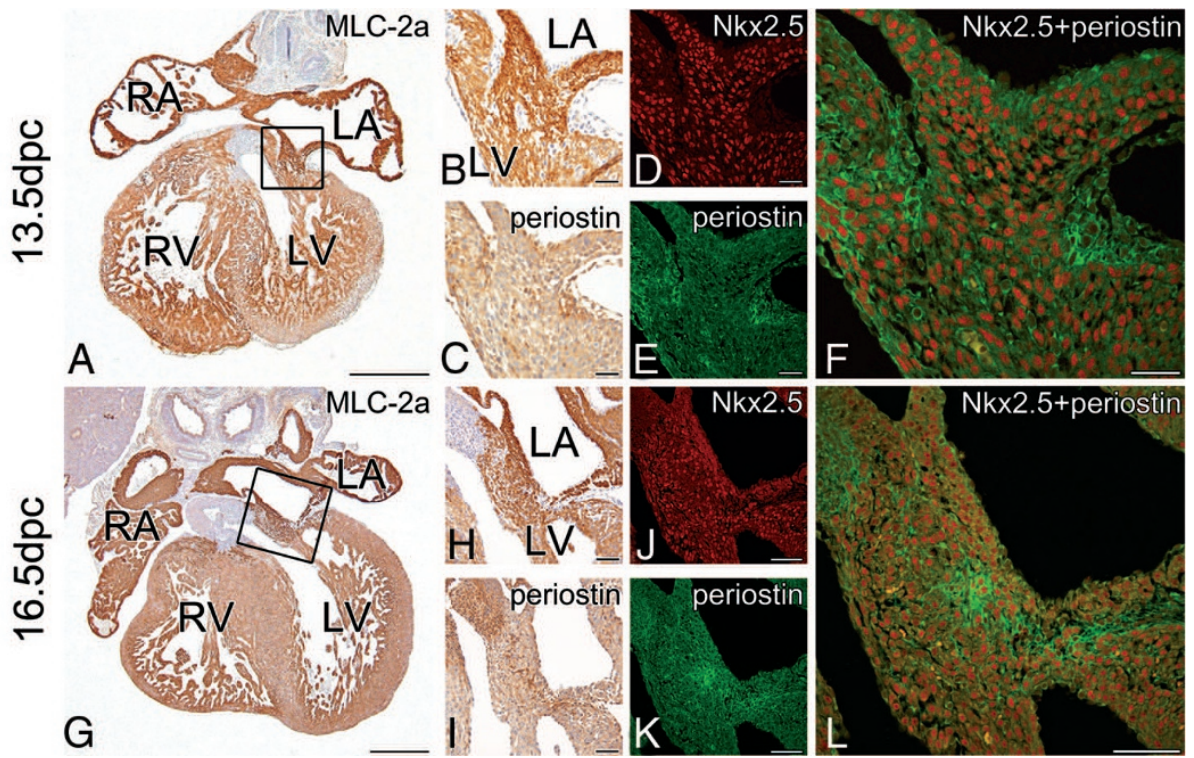

Figure 6. Nkx2.5 and periostin double expression in the developing annulus fibrosus and persistent APs. (A) Frontal MLC-2a-stained section of an early postseptated heart of $13.5 \mathrm{dpc}$. The boxed area in $(A)$ shows a left-sided anterolateral AP magnified in $(B)$. Periostin expression was observed next to the MLC-2a positive AP $[(C)$ consecutive of $(A)]$. An immunofluorescent double-stained section shows that this $\mathrm{AP}[(F)$ consecutive section of $(A)]$ was positive for $\mathrm{Nkx} 2.5(D)$ and negative for periostin $(E)$. $(G)$ Frontal section of almost the same area in $(A)$ of a late postseptated MLC-2a-stained heart of 16.5 dpc. $(H)$ Magnification of the boxed area in $(G)$, showing an MLC-2a positive AP, which also is positive for periostin $[(I)$ consecutive section of $(G)]$. Compared with early postseptated stages $(F)$, this AP $[(L)$ immunofluorescent consecutive section of $(A)]$ is comprised of an intermingling network of $\mathrm{Nkx} 2.5$ positive cardiomyocytes $(J)$ and periostin positive fibroblasts $(K)$. RV, right ventricle; LA, left atrium; $\mathrm{LV}$, left ventricle; Scale bars: $A, G=300 \mu \mathrm{m}$; $B-F=30 \mu \mathrm{m} ; H-L=60 \mu \mathrm{m}$. the AV cushion-derived AV valves including their tension apparatus as well as in the endothelial lining of the developing coronary vessels. Remarkably, periostin was absent in parts of the AV conduction axis, especially in the atrioventricular node (data not shown). Periostin expression was clearly present in the developing annulus fibrosus. Strongest expression was observed at the immediate border between the developing annulus fibrosus and AV canal myocardium (Fig. 6A-C and $G-I)$. Furthermore, high expression of periostin seemed to overlap with the MLC-2a positive APs around both the mitral and tricuspid orifice (Fig. 6I).

Immunofluorescent double stained sections with periostin and Nkx2.5 were used to study the developing annulus fibrosus in relation to the AP cardiomyocytes (Fig. $6 D-F$ and $J-L$ ). At all developmental stages, periostin was strongly expressed in fibroblasts bordering AP cardiomyocytes (11.5-18.5 dpc); however, no periostin expression could be demonstrated in Nkx2.5 positive cardiomyocytes themselves (Fig. $6 F$ and $L$ ).

At early postseptated stages $(13.5 \mathrm{dpc})$, low periostin expression was observed at the anterior side of the left AV junction in almost all hearts, corresponding to the location of the left anterolateral APs. These broad APs were positive for the myocardial markers MLC-2a and Nkx2.5 but negative for periostin (Fig. 6A-F). At later postseptated stages $(>16.5$ $\mathrm{dpc})$, expression of periostin increased at these specific areas (Fig. 6G-L).

\section{DISCUSSION}

AVRT is a relatively common tachyarrhythmia in fetuses and neonates, which seems to resolve in the majority of cases during the first year of life $(1,2)$. It has been suggested that APs involved in these tachycardias are remnants of the primary AV canal myocardium, which disappear during development and maturation of the annulus fibrosus before and after birth $(12,18)$. Although presence of APs has been demonstrated during normal cardiac development in human fetuses and neonates, their etiology and conducting properties as well as their causative role in AVRT are largely unrevealed
(17-20). It is known that APs can be associated with congenital heart disease specifically with abnormal tricuspid valve development like in Morbus Ebstein (21). In a minority of cases, genetic mutations are involved $(22,23)$, like PRKAG2 in familial Wolff-Parkinson-White preexcitation syndrome (24) or in $A l k 3$, which results in a disrupted annulus fibrosus with Cx43 positive APs in mouse (5).

AP location in relation to arrhythmias. The conducting properties of the primitive AV canal myocardium has recently been demonstrated in mouse embryos (15). Here, we show that annulus fibrosus development occurs near the Cx43 negative AV canal myocardium (25). Furthermore, the presence of antegrade conducting Cx43 negative APs were demonstrated, which significantly decreased in number and size along normal mouse heart development, but sometimes remained present at late postseptated stages (Fig. 5).

Recently, similar APs were demonstrated during normal quail heart development, where most APs were found at the posteroseptal aspect of the tricuspid valve orifice (12). In contrast, we demonstrated the majority of APs at the anterolateral aspect of mitral orifice in mouse. In quail, the preferential location of right posteroseptal APs might be explained by the physiological delay of right ventricular inflow tract formation with prolonged isolation of this part of the annulus fibrosus (16). This might also shed light on the observation that occasionally right-sided APs directly penetrate through the annulus fibrosus, whereas left-sided APs rather more frequently skirt the annulus and have a more epicardial position as observed in autopsy studies of human WolffParkinson-White syndrome (26). It seems tempting to postulate that APs that directly penetrate the isolating annulus, as observed in the current study, are related to normal AV junction isolation and disappear along fetal and early postnatal life.

Interestingly, the left anterolateral APs observed in late postseptated embryonic mouse hearts have been reported in studies on cardiac conduction system (CCS) development by means of CCS-lacZ expression. Bundles of lacZ expressing 
cardiomyocytes were observed at the same left anterolateral position at the developing $\mathrm{AV}$ junction, which did not form part of the developing CCS. In some hearts, these bundles could be traced until postnatal stages and have been related to Wolff-Parkinson-White syndrome (14).

Differences with respect to morpho-histology and electrophysiology were noticed between the mitral and tricuspid valve orifice. In early postseptated hearts, a significant majority of APs were observed around the mitral valve orifice, and also the largest total AP- width was found in this area both in early and late postseptated hearts. These histological findings seem to correlate with the electrophysiological recordings showing that in the majority of base-to-apex activated postseptated hearts, the LVB (and not the RVB) is activated prior or concurrent to the LVA. However, a coincidental relationship cannot be expelled, because a direct relation between morphologically observed APs and their individual ability to conduct could not be made (12). Especially at early postseptated stages, multiple APs are present of which some might act as innocent bystanders, i.e. not able to conduct.

Recently, we demonstrated the presence of APs during human heart development, which also decreased along embryonic and fetal life (18). It remains to be determined whether these physiological APs in human are functional and can form the substrates for AVRT. Interestingly, APs involved in AVRT are more often located around the mitral valve orifice (27), which seems to correspond to the high frequency of conducting left-sided APs as observed in the current study.

Periostin expression in relation to annulus fibrosus formation and persistent APs. Periostin is expressed in the developing annulus fibrosus $(12,18)$, specifically at locations where separation of atrial and ventricular myocardium is needed. At these regions, periostin might induce formation of isolating fibrous tissue, as it directly regulates collagen-I fibrillogenesis (8).

The broad Cx43 negative anterolateral APs around the mitral orifice, which most probably have an imperative role in the large group of early LVB and concurrent activated hearts, were predominantly periostin negative at early postseptated stages. This seems to indicate that only APs negative for periostin are able to conduct, which correspond to recent findings of electrophysiological studies in neonatal mouse hearts (5). At later stages, periostin expression increases near the left anterolateral APs, suggesting an active process of isolation in that particular region. Interestingly, annulus fibrosus formation is not strictly limited to the prenatal stages, because contemporary studies demonstrated that formation of the fibrous structures of the heart extends into early postnatal development $(28,29)$. Therefore, we postulate that periostin has an important role in AV junction isolation by stimulation of fibrous tissue formation, thereby separating atrial and ventricular myocardium, which subsequently will lead to regression of conducting APs pre- and postnatally.

The regulation of periostin and the exact way it contributes in annulus fibrosus formation remain to be elucidated. However, it has been demonstrated that several growth factors including bone morphogenetic proteins (BMPs) (30), TGF- $\beta$ (7) and PDGFs (31) are involved, which are highly expressed in the developing AV region. In addition, state-of-art studies performed in avian hearts indicated that epicardium-derived cells play a key role in periostin regulation involved in annulus fibrosus development. Inhibition of early epicardial outgrowth, resulted in a disturbed annulus fibrosus development coinciding with a high frequency of periostin negative antegrade conducting APs $(10,11)$.

\section{CONCLUSION}

The current study demonstrates that antegrade conducting APs, which are remnants of $\mathrm{Cx} 43$ negative primitive AV canal myocardium, remain present until late fetal stages of normal mouse heart development. These conducting APs can act as substrate for AVRT. Ongoing formation and maturation of the annulus fibrosus in which periostin seems to have an important role may explain spontaneous resolution of these arrhythmias in fetuses and neonates.

\section{REFERENCES}

1. Bauersfeld U, Pfammatter JP, Jaeggi E 2001 Treatment of supraventricular tachycardias in the new millennium-drugs or radiofrequency catheter ablation? Eur J Pediatr 160:1-9

2. Ko JK, Deal BJ, Strasburger JF, Benson DW Jr 1992 Supraventricular tachycardia mechanisms and their age distribution in pediatric patients. Am J Cardiol 69:10281032

3. Naheed ZJ, Strasburger JF, Deal BJ, Benson DW Jr, Gidding SS 1996 Fetal tachycardia: mechanisms and predictors of hydrops fetalis. J Am Coll Cardiol 27:1736-1740

4. Wessels A, Markman MW, Vermeulen JL, Anderson RH, Moorman AF, Lamers WH 1996 The development of the atrioventricular junction in the human heart. Circ Res 78:110-117

5. Gaussin V, Morley GE, Cox L, Zwijsen A, Vance KM, Emile L, Tian Y, Liu J, Hong C, Myers D, Conway SJ, Depre C, Mishina Y, Behringer RR, Hanks MC, Schneider MD, Huylebroeck D, Fishman GI, Burch JB, Vatner SF 2005 Alk3/Bmpr1a receptor is required for development of the atrioventricular canal into valves and annulus fibrosus. Circ Res 97:219-226

6. Okagawa H, Markwald RR, Sugi Y 2007 Functional BMP receptor in endocardial cells is required in atrioventricular cushion mesenchymal cell formation in chick. Dev Biol 306:179-192

7. Horiuchi K, Amizuka N, Takeshita S, Takamatsu H, Katsuura M, Ozawa H, Toyama Y, Bonewald LF, Kudo A 1999 Identification and characterization of a novel protein, periostin, with restricted expression to periosteum and periodontal ligament and increased expression by transforming growth factor beta. J Bone Miner Res 14:1239-1249

8. Norris RA, Damon B, Mironov V, Kasyanov V, Ramamurthi A, Moreno-Rodriguez R, Trusk T, Potts JD, Goodwin RL, Davis J, Hoffman S, Wen X, Sugi Y, Kern CB, Mjaatvedt CH, Turner DK, Oka T, Conway SJ, Molkentin JD, Forgacs G, Markwald RR 2007 Periostin regulates collagen fibrillogenesis and the biomechanical properties of connective tissues. J Cell Biochem 101:695-711

9. Kruzynska-Frejtag A, Machnicki M, Rogers R, Markwald RR, Conway SJ 2001 Periostin (an osteoblast-specific factor) is expressed within the embryonic mouse heart during valve formation. Mech Dev 103:183-188

10. Kolditz DP, Wijffels MC, Blom NA, van der Laarse A, Hahurij ND, Lie-Venema H, Markwald RR, Poelmann RE, Schalij MJ, Gittenberger-De Groot AC 2008 Epicardium-derived cells in development of annulus fibrosis and persistence of accessory pathways. Circulation 117:1508-1517

11. Lie-Venema H, Eralp I, Markwald RR, Van Den Akker NM, Wijffels MC, Kolditz DP, van der Laarse A, Schalij MJ, Poelmann RE, Bogers AJ, Gittenberger-De Groot AC 2008 Periostin expression by epicardium-derived cells is involved in the development of the atrioventricular valves and fibrous heart skeleton. Differentiation 76:809-819

12. Kolditz DP, Wijffels MC, Blom NA, van der Laarse A, Markwald RR, Schalij MJ, Gittenberger-De Groot AC 2007 Persistence of functional atrioventricular accessory pathways in postseptated embryonic avian hearts: implications for morphogenesis and functional maturation of the cardiac conduction system. Circulation 115:17-26

13. Chuck ET, Freeman DM, Watanabe M, Rosenbaum DS 1997 Changing activation sequence in the embryonic chick heart. Implications for the development of the His-Purkinje system. Circ Res 81:470-476

14. Rentschler S, Vaidya DM, Tamaddon H, Degenhardt K, Sassoon D, Morley GE, Jalife J, Fishman GI 2001 Visualization and functional characterization of the developing murine cardiac conduction system. Development 128:1785-1792

15. Valderrábano M, Chen F, Dave AS, Lamp ST, Klitzner TS, Weiss JN 2006 Atrioventricular ring reentry in embryonic mouse hearts. Circulation 114:543-549

16. Jongbloed MR, Wijffels MC, Schalij MJ, Blom NA, Poelmann RE, van der Laarse A, Mentink MM, Wang Z, Fishman GI, Gittenberger-De Groot AC 2005 Develop- 
ment of the right ventricular inflow tract and moderator band: a possible morphological and functional explanation for Mahaim tachycardia. Circ Res 96:776-783

17. Robb JS, Kaylor CT, Turman WG 1948 A study of specialized heart tissue at various stages of development of the human fetal heart. Am J Med 5:324-336

18. Hahurij ND, Gittenberger-De Groot AC, Kolditz DP, Bokenkamp R, Schalij MJ, Poelmann RE, Blom NA 2008 Accessory atrioventricular myocardial connections in the developing human heart: relevance for perinatal supraventricular tachycardias. Circulation 117:2850-2858

19. James TN 1994 Normal and abnormal consequences of apoptosis in the human heart From postnatal morphogenesis to paroxysmal arrhythmias. Circulation 90:556-573

20. Truex RC, Bishof JK, Hoffman EL 1958 Accessory atrioventricular muscle bundles of the developing human heart. Anat Rec 131:45-59

21. Smith WM, Gallagher JJ, Kerr CR, Sealy WC, Kasell JH, Benson DW Jr, Reiter MJ, Sterba R, Grant AO 1982 The electrophysiologic basis and management of symptomatic recurrent tachycardia in patients with Ebstein's anomaly of the tricuspid valve. Am J Cardiol 49:1223-1234

22. Vidaillet HJ Jr, Pressley JC, Henke E, Harrell FE Jr, German LD 1987 Familia occurrence of accessory atrioventricular pathways (preexcitation syndrome). N Engl J Med 317:65-69

23. Roberts R 2006 Genomics and cardiac arrhythmias. J Am Coll Cardiol 47:9-21

24. Gollob MH, Green MS, Tang AS, Gollob T, Karibe A, Ali Hassan AS, Ahmad F, Lozado R, Shah G, Fananapazir L, Bachinski LL, Roberts R 2001 Identification of a gene responsible for familial Wolff-Parkinson-White syndrome. N Engl J Med 344:1823-1831

25. Delorme B, Dahl E, Jarry-Guichard T, Briand JP, Willecke K, Gros D, TheveniauRuissy M 1997 Expression pattern of connexin gene products at the early developmental stages of the mouse cardiovascular system. Circ Res 81:423-437

26. Becker AE, Anderson RH, Durrer D, Wellens HJ 1978 The anatomical substrates of wolff-parkinson-white syndrome. A clinicopathologic correlation in seven patients. Circulation 57:870-879

27. Strasburger JF, Cheulkar B, Wichman HJ 2007 Perinatal arrhythmias: diagnosis and management. Clin Perinatol 34:627-652

28. Visconti RP, Markwald RR 2006 Recruitment of new cells into the postnatal heart: potential modification of phenotype by periostin. Ann N Y Acad Sci 1080:19-33

29. Kruithof BP, Krawitz SA, Gaussin V 2007 Atrioventricular valve development during late embryonic and postnatal stages involves condensation and extracellular matrix remodeling. Dev Biol 302:208-217

30. Inai K, Norris RA, Hoffman S, Markwald RR, Sugi Y 2008 BMP-2 induces cell migration and periostin expression during atrioventricular valvulogenesis. Dev Biol 315:383-396

31. Lindner V, Wang Q, Conley BA, Friesel RE, Vary CP 2005 Vascular injury induces expression of periostin: implications for vascular cell differentiation and migration. Arterioscler Thromb Vasc Biol 25:77-83 